\title{
Theoretical and Experimental Aspects Regarding the Forced Mounting of a Cylinder Containing the Electronics of a Mini Submarine
}

\author{
Amado-George Ștefan ${ }^{1}$, Lucian Ștefăniță Grigore ${ }^{1}$, Silvia Marzavan ${ }^{1}$, Iustin Priescu ${ }^{2}$ and Ionica Oncioiu ${ }^{3, *(D)}$ \\ 1 Center of Excellence in Robotics and Autonomous Systems-CERAS, Military Technical Academy, \\ "FERDINAND I", 39-49 George Coșbuc Av., 050141 Bucharest, Romania; amado.stefan@mta.ro (A.-G.S.); \\ lucian.grigore@mta.ro (L.Ș.G.); silvia.marzavan@mta.ro (S.M.) \\ 2 Department of Informatics, Faculty of Informatics, Titu Maiorescu University, \\ 040051 Bucharest, Romania; iustin.priescu@prof.utm.ro \\ 3 Faculty of Finance-Banking, Accountancy and Business Administration, Titu Maiorescu University, \\ 040051 Bucharest, Romania \\ * Correspondence: ionica.oncioiu@prof.utm.ro; Tel.: +40-372-710-962
}

check for

updates

Citation: Ștefan, A.-G.; Grigore, L.S.,; Marzavan, S.; Priescu, I.; Oncioiu, I.

Theoretical and Experimental Aspects Regarding the Forced Mounting of a Cylinder Containing the Electronics of a Mini Submarine. J. Mar. Sci. Eng. 2021, 9, 855. https://doi.org/ $10.3390 /$ jmse9080855

Academic Editors: Rafael Morales and David Moreno-Salinas

Received: 8 July 2021

Accepted: 4 August 2021

Published: 8 August 2021

Publisher's Note: MDPI stays neutral with regard to jurisdictional claims in published maps and institutional affiliations.

Copyright: (c) 2021 by the authors. Licensee MDPI, Basel, Switzerland. This article is an open access article distributed under the terms and conditions of the Creative Commons Attribution (CC BY) license (https:/ / creativecommons.org/licenses/by/ $4.0 /)$.

\begin{abstract}
The underwater robot is part of a project with "terrestrial-maritime" collaborative robots, whose mission is recognition and rescue. From a structural point of view, some small changes were made in this study to the original robot. These changes consisted of making supports to hold the two plexiglass tubes, since the tube containing the battery system is larger. A larger tube was chosen because the aim was to increase the travel autonomy of the mini remotely operated vehicle (ROV). The mini submarine will move in an unstructured environment and will be able to reach a depth of $100 \mathrm{~m}$. The purpose of the article is to present a point of view regarding the effect of the behavior of the mini ROV on tensions produced by the forced assembly of the sealing cover of the cylinder containing its command-and-control system. Both the gripping elements and the sealing lids are made using 3D printing technology, and the material used is polylactic acid (PLA). For the numerical analysis, the finite element method is used in both static and dynamic conditions. The results of this work refer to the field of tensions and displacements. The main conclusions emphasize the fact that the gripping performed for sealing is influenced by the usage of oiled mechanisms.
\end{abstract}

Keywords: submarine; robot; autonomous underwater maritime; plexiglass; displacement

\section{Introduction}

The remotely operated vehicle (ROV) for which the current study has been performed is a part of the autonomous underwater maritime (AUM) family, which is defined as generic underwater maritime vehicles that are capable of autonomous functioning, without a remote control system [1-4]. They are considered very useful for activities such as mapping, topography, surveillance, and underwater management [5-9].

Robots in this size category are used especially for inspection, control, and lowmaintenance activities with underwater objectives, such as trolley installations or inspection of oil pipelines, communication cables, electrical cables, etc. [10-14].

The overall dimensions and equipment (payload) that can be attached to these ROVs are advantages over larger autonomous underwater vehicles (AUVs), as they make the vehicles much easier to control and can transmit a large amount of data over a short time [15-17].

Another advantage of ROVs is increased maneuverability: the vehicles have a high speed of travel, can stabilize against certain conditions of sea currents, and can sneak into fairly tight spots [18-20]. 
The types of missions presented so far are not the only ones that mini submarines can perform. For example, they can even be used to bury communication cables, electrical cables, or water pipes on the seabed [21-23].

Perhaps some of the most spectacular missions that can be performed by mini submarines are those in support of the naval military forces [24]. At sea, the theaters of operations and the naval bases are subject to a multitude of challenges due to humans and the environment. That is why there is growing interest in making these underwater ROVs into AUVs [25-28].

The next scenario regarding the development of AUVs was the realization of cooperative collaboration systems between submarine robots [29-33].

All this can be made possible if the robot, from a mechanical and hydrodynamic point of view, responds to the challenges it faces in meeting the demands upon it [34-36].

The present study presents the outcomes of gripping a lid for sealing in two situations: without oil and with oil for the mechanisms. The cylinder body was made of plexiglass, and for the sealing caps, polylactic acid (PLA) printed using 3D printing technology was used. SolidWorks software was used to design the mini submarine. Tensometric marks were used to analyze the behavior of the cylinder when reacting to demands due to the introduction of the sealing caps. The QUANTUMX MX1615 module was used to take and analyze data from tensometric marks, and the MX840B module was used for force and displacement sensors.

The ROV developed in the Center of Excellence in Robotics and Autonomous Systems (CERAS) allows the performance of specific activities up to the maximum depth of $100 \mathrm{~m}$ (Figure 1) [37]. It can transport command-and-control equipment, video cameras and sensors, sonar, an actuator system, and performing elements (e.g., articulated arms for gripping) [7-9].

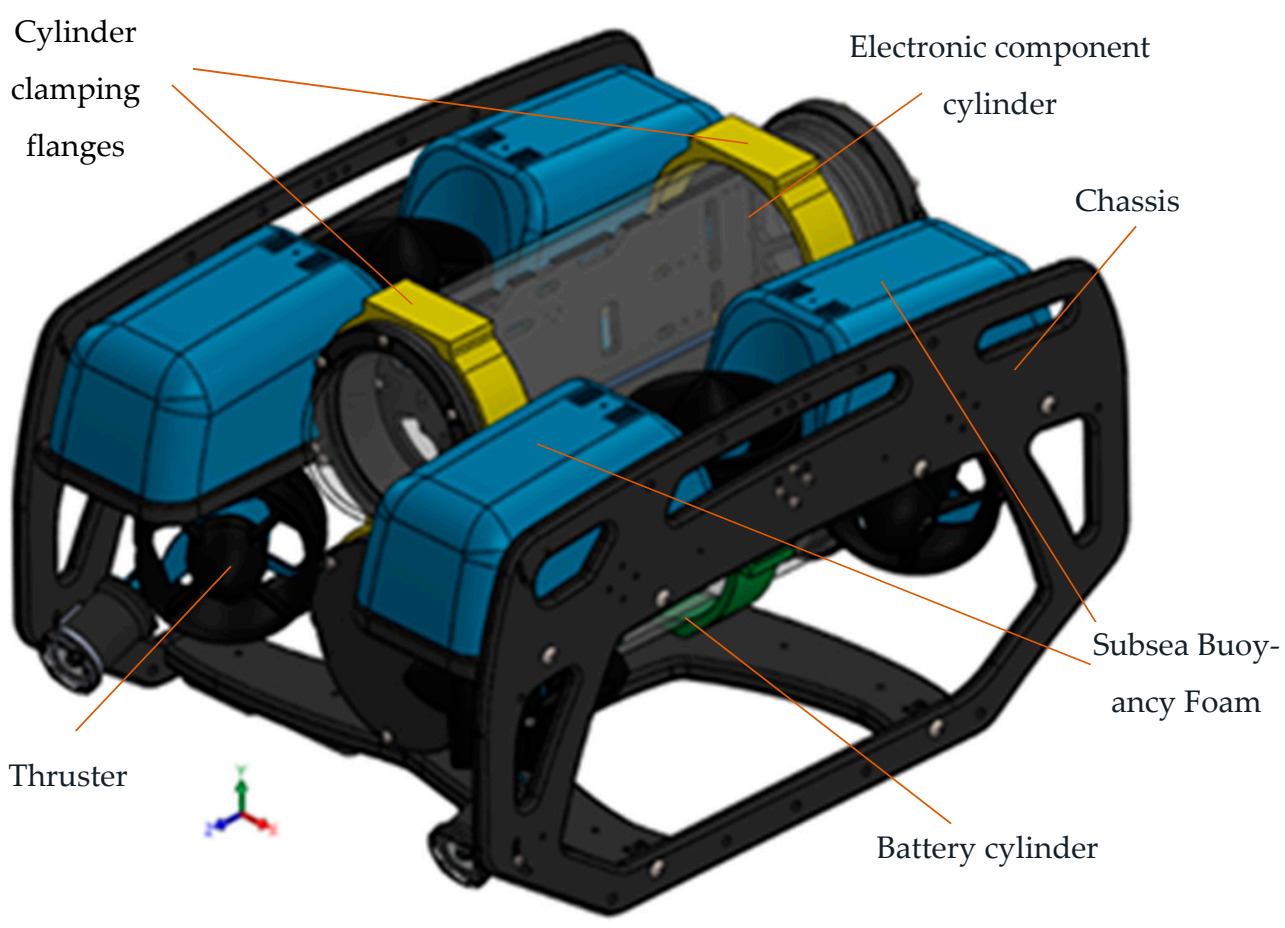

Figure 1. ROV used for recognition and rescue missions.

Its originality is given by several elements, such as:

- It being a collaborative robot that communicates independently with a senile ground robot to perform complex intervention and rescue missions [38,39];

- It having an increased energy resource with lithium-ion (Li-Ion) batteries (14.8 V, $18 \mathrm{Ah}$ ), which gives it increased autonomy [40]; 
- The mechanical elements being printed on a PRUSA 3D printer, using PLA as the material, which is a thermoplastic polyester of the chemical formula $\left(\mathrm{C}_{3} \mathrm{H}_{4} \mathrm{O}_{2}\right) \mathrm{n}$. This is one of the most common materials; though it has many physical and processing deficiencies, it allows us to change the design of the mini submarine according to the different missions [41-43].

The purpose of the study presented in this article is to determine experimentally and theoretically the state of tension in the cylinder body after mounting the sealing caps and to determine the possibility of this mounting without cracking the cylinder body.

Another novelty is the fact that the leakage tests were performed before moving on to the assembly of the cylinder with sealing caps on the mini submarine. Through this operation, it was possible to perform a check of the tightness of the cylinder to protect the command-and-control system.

This paper presents the results of efforts to build an AUV as part of a complex of two collaborative robots, the second being an unmanned ground vehicle (UGV). This system of two collaborative robots will be able to perform complex tasks of physical intervention to limit the negative effects due to a system of oil-supply pipelines and recovery of people from both land and sea. Regarding the relevant aspects of this paper, we highlight the fact that the structural elements are 3D printed, and we study the tightness of the bodies in which the electronic components and the power supply system are located.

Accordingly, in this study, by simulations with finite element method (FEM) and by force-machine tests, it is shown that the plexiglass tubes are sealed so that the AUV can be submerged to a maximum depth of $100 \mathrm{~m}$.

This paper is structured as follows: in Section 2, we describe the materials and methods; the following Section 2 presents the numerical method for simulating the forced mounting of the cover in the cylinder; Section 4 presents the experimental results for mounting the cover in the cylinder, and finally, the conclusions are presented.

\section{Materials and Methods}

The study focused on the tensions produced by the forced mounting of the sealing lid in the cylinder that contains the electronics of the mini submarine, along with the force necessary for the Figure 2 mounting [44].

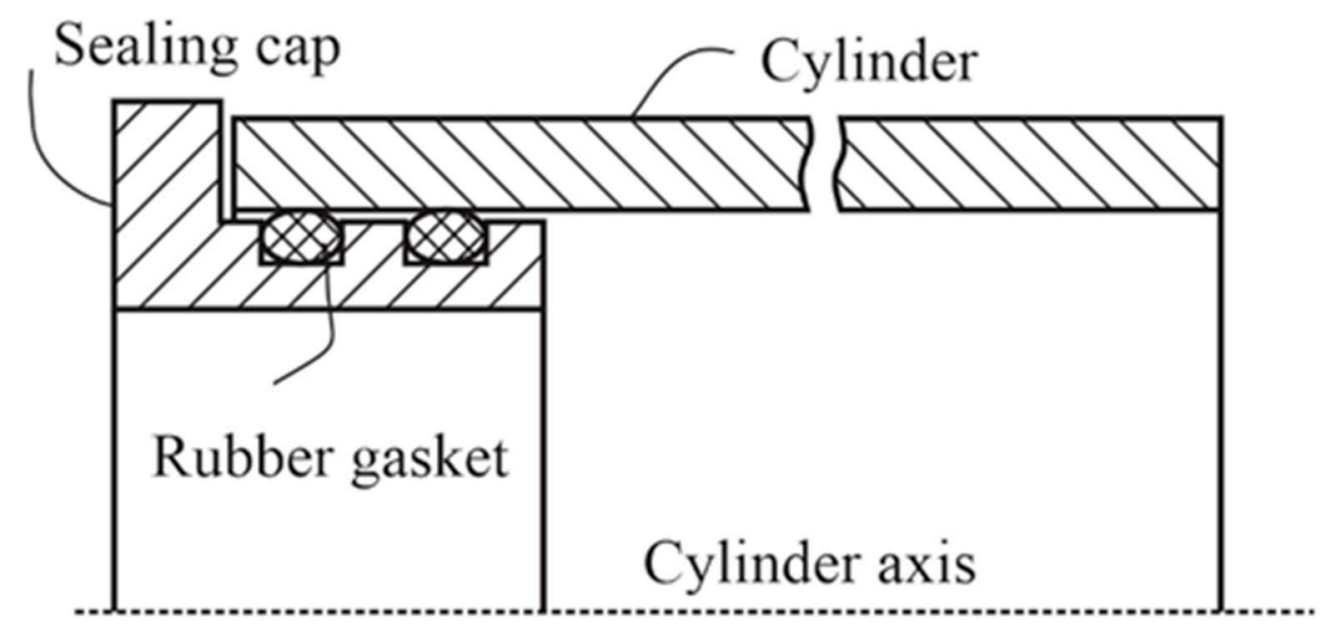

Figure 2. The schematics of the underwater ROV command-and-control cylinder sealing system.

In practice, there are currently problems in which a curved cylindrical plate is subject to the actions of symmetrically distributed forces for the axis of the cylinder: the tension distribution in the boilers subject to the action of steam pressure, the tensions in the vertical cylindrical tanks subject to the pressure exerted by the liquid inside, and the tensions from the circular pipes subject to the uniform internal pressure are examples of such problems. 
To establish the equations necessary to determine the solutions to these problems, we take into consideration a plate element, schematically represented through the median surface as shown in Figure 3. The sides of the plate elements $A D=B C=d x$ and the curved sides $A B$ and $C D$ are circle arcs with a radius equal to the radius of the cylinder, their length being $R d \varphi$. The $O x$ axis is oriented along the cylinder's generator; the $O \varphi$ axis is a tangent to the cylindrical surface in a normal plane to the axis of the cylinder; the $\mathrm{Oz}$ axis follows the normal to the surface of the cylinder, oriented with a positive direction towards the axis of the cylinder.
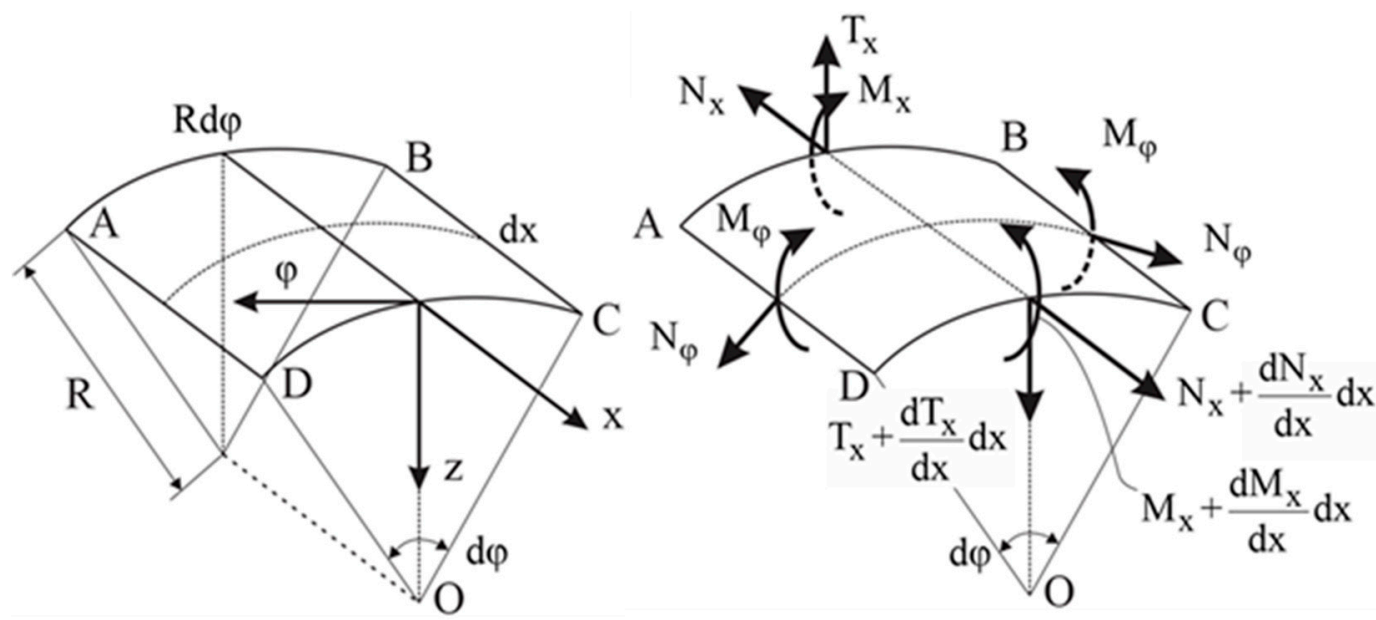

Figure 3. The scheme of an infinitesimal element of cylindrical plate: $\varphi$ — the opening angle of the infinitesimal element; $R$-radius of the infinitesimal element; $N_{x}$-axial force; $T_{x}$-normal force; $M_{x}, M_{\varphi}$ 一torsion torques; $N_{\varphi}$-shear forces from the median surface; $T_{\varphi}$-shear forces normal to the median surface.

The load of the cylindrical curve plate is axially symmetric, being distributed normally on the surface of the plate (written as $q_{z}$ ).

Due to the axially symmetric load of the cylindrical plate, the asymmetric sectional efforts that depend on the $\varphi$ variable are null. The following occurs in this situation: the shear forces from the median surface $N_{\varphi}=N_{\varphi x}=0$ (membrane theory), the shear forces normal to the median surface $T_{\varphi}=0$, and torsion torques $M_{x \varphi}=M_{\varphi x}=0$. Additionally, due to the symmetry, $N_{\varphi}$ and $M_{\varphi}$ depend only on the $x$ variable, being constant in relation to $\varphi$.

By noting the equilibrium equations for the cylindrical plate element [11], we have:

$$
\left\{\begin{array}{l}
\frac{d N_{x}}{d x}=0 \\
\frac{d T_{x}}{d x}+\frac{1}{a} N_{\varphi}=-q_{z} \\
\frac{d M_{x}}{d x}=T_{x}
\end{array},\right.
$$

From the first relation, the axial force $N_{x}$ is constant and can be further considered null. The two remaining equations contain three unknown variables: $T_{x}, T_{\varphi}$, and $M_{x}$. To solve this problem, we analyze the displacements of the points from the median surface of the plate. Due to the axial symmetry, the points can move along the axis of the cylinder (the $\mathrm{Oz}$ axis). If we use the established notations $-u$, the displacement along the $O x$ axis, $v$, the displacement along the $O \varphi$ axis, and $w$, along the $O z$ axis - then $v$ is null at any point of the plate, while $u$ and $w$ depend only on the $x$ variable, from which the normal tensions can be written as:

$$
\left\{\begin{array}{l}
\varepsilon_{x}=\frac{d u}{d x} \\
\varepsilon_{\varphi}=-\frac{w}{R}
\end{array},\right.
$$


and the normal tensions become:

$$
\left\{\begin{array}{l}
\sigma_{x}=\frac{E}{1-\mu^{2}}\left(\varepsilon_{x}+\mu \varepsilon_{\varphi}\right) \\
\sigma_{\varphi}=\frac{E}{1-\mu^{2}}\left(\varepsilon_{\varphi}+\mu \varepsilon_{x}\right)
\end{array},\right.
$$

from which the integrated tensions from the faces of the elements between the inner and outer surfaces become (where $h$ is the width of the plate):

$$
\left\{\begin{array}{l}
N_{x}=\int_{-\frac{h}{2}}^{\frac{h}{2}} \sigma_{x} d z=\frac{E h}{1-\mu^{2}}\left(\frac{d u}{d x}-\mu \frac{w}{R}\right)=0 \\
N_{\varphi}=\int_{-\frac{h}{2}}^{\frac{h}{2}} \sigma_{\varphi} d z=\frac{E h}{1-\mu^{2}}\left(-\frac{w}{R}+\mu \frac{d u}{d x}\right)=0
\end{array} .\right.
$$

From the expression of $N_{x}$ we have $\frac{d u}{d x}=\mu \frac{w}{R}$, which leads to the expression of the $N_{\varphi}$ force as a function of the $w$ displacement:

$$
N_{\varphi}=-\frac{E h}{R} \cdot w .
$$

Deriving, in relation to $x$, the last relation in the system (1), and replacing it in this relation (2), the following differential equation allows the computation of the $w$ displacement:

$$
\frac{d^{2}}{d x^{2}}\left(D \frac{d^{2} w}{d x^{2}}\right)+\frac{E h}{R^{2}} w=q_{z}
$$

If the rigidity is constant due to the constant width of the plate as a function of $x$, the differential Equation (6) is of the fourth order, with constant coefficients and a nonhomogenous nature. If we write $\beta^{4}=\frac{E h}{4 R^{2} D}=\frac{3\left(1-\mu^{2}\right)}{R^{2} h^{2}}$, then the general solution will be given by:

$$
\begin{aligned}
w(x) & =e^{\beta x}\left[C_{1} \cos (\beta x)+C_{2} \sin (\beta x)\right]+ \\
& +e^{-\beta x}\left[C_{3} \cos (\beta x)+C_{4} \sin (\beta x)\right]+w_{p}(x)
\end{aligned}
$$

where $w_{p}$ is a particular solution.

For the situation in which the curved cylindrical plate is loaded by a shear force and a bending torque in a section from the base of the cylinder (Figure 4), the force distributed on the lateral surface, $q_{z}$, is null.

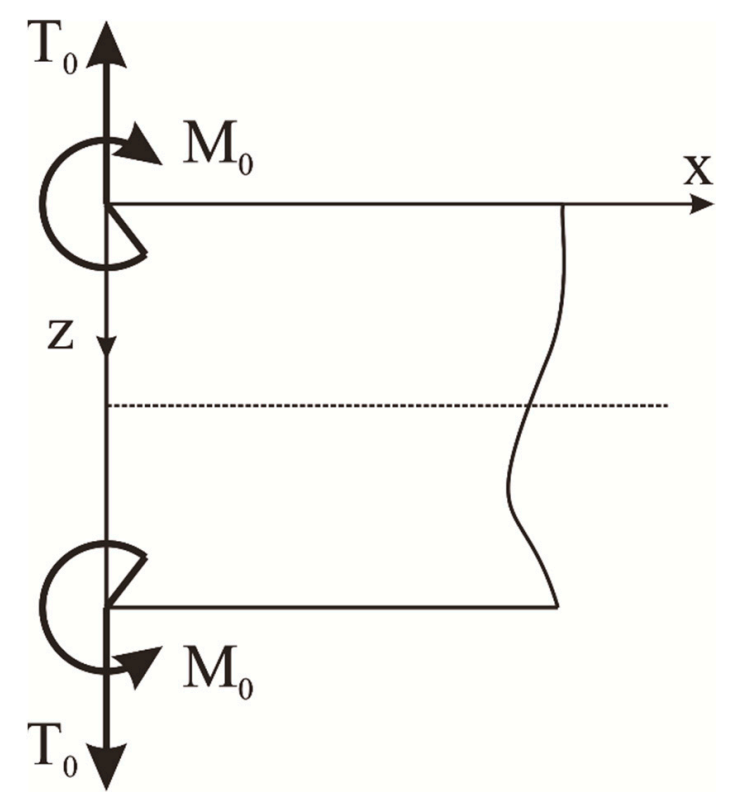

Figure 4. Boundary conditions. 
In this situation, the differential Equation (7) becomes homogenous, and the generalized solution has the following form:

$$
\begin{gathered}
w(x)=e^{\beta x}\left[C_{1} \cos (\beta x)+C_{2} \sin (\beta x)\right]+ \\
+e^{-\beta x}\left[C_{3} \cos (\beta x)+C_{4} \sin (\beta x)\right]
\end{gathered}
$$

The reduction tensor of the load is null relative to any point. If the length of the cylinder is high (tends to infinity), the displacement of the points on the median surface in the radial direction decreases while $x$ increases. This aspect is due to Saint-Venant's principle. At a distance high enough from the section subjected to the load, it can be considered that the $w$ displacement is null, and as a consequence, the positive exponential does not have to appear in the expression of the displacement (the $C_{1}=C_{2}=0$ constants). In this situation, the solution has the following form:

$$
w(x)=e^{-\beta x}\left[C_{3} \cos (\beta x)+C_{4} \sin (\beta x)\right] .
$$

In the studied case, two distributed forces act constantly on circular sections placed at different distances relative to the lid of the cylinder. The two forces come from the action of the rubber gaskets upon the cylinder. These forces represent the mechanical equivalent of the distribution of contact forces on the contact area, which due to being narrow, is equivalent to a circle placed on the inner surface of the cylinder. To avoid complicating the issue, the case of a single force that acts at a distance $L$ from the end of the cylinder will be studied, after which the effects of two forces placed at different distances will be overlapped. The coordinate system is chosen with the origin as the point where the force acts (Figure 5).

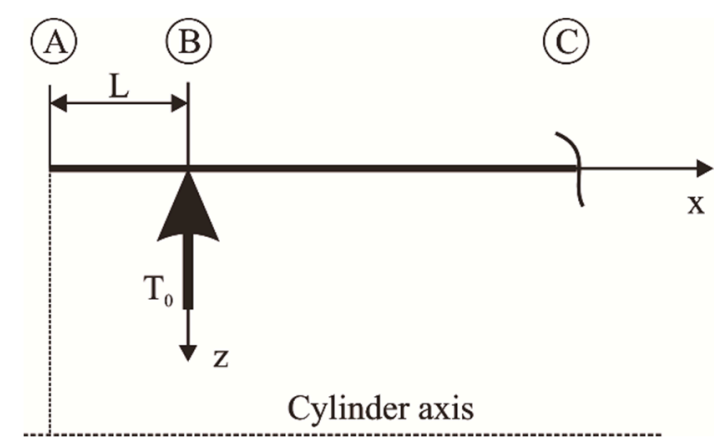

Figure 5. Particular case: the shear force $T_{0}$ acts at the $\mathrm{L}$ distance to the end of the cylinder.

The displacements of the points from the median surface, written as $w_{1}$ for the $A B$ interval and $w_{2}$ for $B C$, will be taken into consideration. The $L$ length of the $A B$ interval is small compared to the length of the cylinder, and as a consequence, the positive exponential will no longer be neglected, the form of the displacement being the one in (8). For the $B C$ interval, the displacement remains of the form (9):

$$
\left\{\begin{array}{c}
w_{1}(x)=e^{\beta x}\left[C_{1} \cos (\beta x)+C_{2} \sin (\beta x)\right]+ \\
+e^{-\beta x}\left[C_{3} \cos (\beta x)+C_{4} \sin (\beta x)\right] \\
w_{2}(x)=e^{-\beta x}\left[C_{5} \cos (\beta x)+C_{6} \sin (\beta x)\right]
\end{array} .\right.
$$

In this case, we have six unknown variables $\left(C_{1} \ldots C_{6}\right)$, which can be determined using system (11): 


$$
\left\{\begin{array}{l}
\left.w_{1}\right|_{x=0}=\left.w_{2}\right|_{x=0} \\
\left.\frac{d w_{1}}{d x}\right|_{x=0}=\left.\frac{d w_{2}}{d x}\right|_{x=0} \\
\left.M x_{1}\right|_{x=0}=\left.M x_{2}\right|_{x=0} \\
\left.T x_{1}\right|_{x=0}+T_{0}=\left.T x_{2}\right|_{x=0} \\
\left.M x_{1}\right|_{x=-L}=0 \\
\left.T x_{1}\right|_{x=-L}=0
\end{array} .\right.
$$

Solving the system of Equation (11) allows the determination of the coefficients $\left(C_{1} \ldots C_{6}\right)$ :

$$
\left\{\begin{array}{l}
C_{1}=-\frac{T_{0}}{8 D \beta^{3}} \\
C_{2}=\frac{T_{0}\left[1-\cos (2 L \beta)+e^{2 L \beta}\right]}{8 D \beta^{3}[1+\sin (2 L \beta)]} \\
C_{3}=-\frac{T_{0}\left[\cos (2 L \beta)+2 e^{2 L \beta} \cos (L \beta)\right]}{8 D \beta^{3}[1+\sin (2 L \beta)]} \\
C_{4}=\frac{T_{0}}{8 D \beta^{3}} \\
C_{5}=\frac{T_{0}\left[\sin (2 L \beta)+\cos (2 L \beta)+2+e^{-2 L \beta}\right]}{8 D \beta^{3}[1+\sin (2 L \beta)]} \\
C_{6}=-\frac{T_{0}\left[\sin (2 L \beta)+\cos (2 L \beta)-e^{-2 L \beta}\right]}{8 D \beta^{3}[1+\sin (2 L \beta)]}
\end{array} .\right.
$$

At one point from the external surface of the cylinder of $\left(x_{0},-\frac{h}{2}\right)$ coordinates, the tensions become:

$$
\begin{aligned}
& \sigma_{x}\left(x_{0},-\frac{h}{2}\right)=\left\{\begin{array}{l}
\frac{E h}{2\left(1-\mu^{2}\right)} \frac{d^{2} w_{1}\left(x_{0}\right)}{d x^{2}} \text { if } x_{0}<0 \\
\frac{E h}{2\left(1-\mu^{2}\right)} \frac{d^{2} w_{2}\left(x_{0}\right)}{d x^{2}} \text { if } x_{0} \geq 0
\end{array}\right. \\
& \sigma_{\varphi}\left(x_{0},-\frac{h}{2}\right)=\left\{\begin{array}{l}
\frac{\mu E h}{2\left(1-\mu^{2}\right)} \frac{d^{2} w_{1}\left(x_{0}\right)}{d x^{2}}-\frac{E}{R} w_{1}\left(x_{0}\right) \text { if } x_{0}<0 \\
\frac{\mu E h}{2\left(1-\mu^{2}\right)} \frac{d^{2} w_{2}\left(x_{0}\right)}{d x^{2}}-\frac{E}{R} w_{2}\left(x_{0}\right) \text { if } x_{0} \geq 0
\end{array}\right.
\end{aligned} .
$$

Based on the above, we can appreciate that the stresses of the cylindrical curvature plate can be calculated only if we know the force that is acting. This force comes from the compression of the gasket in the channel from the cover to the mounting in the cylinder. An analytical or numerical model of the compressed gasket is required to determine it.

\section{Numerical Model}

To model the forced mounting of the lid in the cylinder with MEF, a planar axial symmetrical model with parallelepipedal finite elements was used. At the initial time, the cylinder was in the proximity of the first gasket. The superior part of the lid was restricted in displacement by the Oy axis and the inferior part of the cylinder by a movement on the Oy axis that increased linearly from 0 to $15 \mathrm{~mm}$ in a time interval of one second, as was imposed.

The mechanical characteristics of the material considered in the analysis with finite elements (from the materials library in SolidWorks) are:

- PLA: linear elastic model material, modulus $3500 \mathrm{MPa}$, Poisson's ratio 0.36;

- PLEXI: linear elastic model material, modulus 3000 MPa, Poisson's ratio 0.37;

- Neoprene rubber: hyper-elastic Mooney Rivlin model material with uniaxial test data.

Friction contacts between the gaskets and the lid with a friction coefficient of 0.4 were defined (due to the quality of the surfaces of the channels inside the lid, which was made via $3 \mathrm{D}$ printing), along with those between the gaskets and the cylinder, with a friction coefficient of 0.1 .

In Figure 6a,b, the equivalent tensions are presented in two positions of the cylinder: when it covers the first gasket and when sealing is performed. The gasket has a circular section with a diameter of $3.5 \mathrm{~mm}$; the G plexiglass cylinder has an outer diameter of $110 \mathrm{~mm}$ and the inner one of $100 \mathrm{~mm}$. It can be noted that the maximum tension from the 
cylinder is $1.77 \mathrm{MPa}$, a value that does not exceed the breaking tension indicated by the manufacturer of $72 \mathrm{MPa}$.

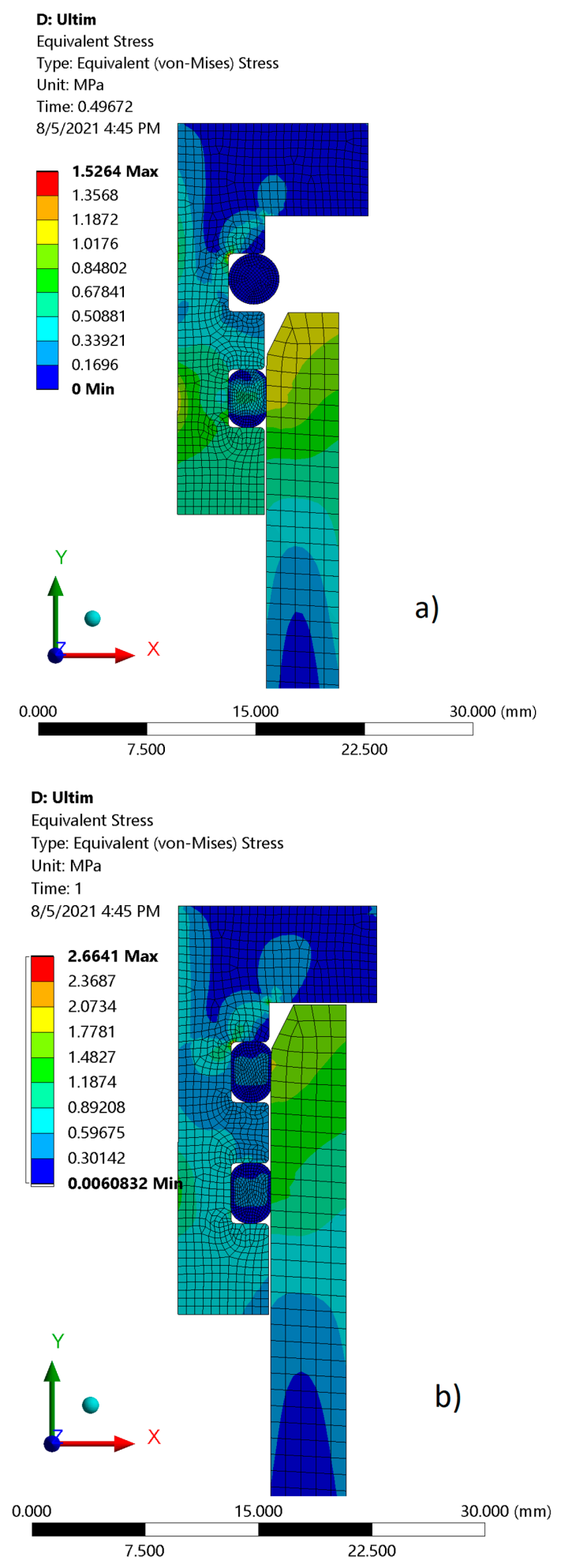

Figure 6. Particular case: the shear force $T_{0}$ acts at a distance $L$ from the end of the cylinder. (a) is the beginning of pushing the sealing cover, and (b) is the end of closing the sealing cover. You can also see how the stresses inside the rubber gaskets change.

The principle of the experimental method is as follows: 
1. Stick the tensometric marks on the cylinder: place a mark on the direction of the generator at a distance of $40 \mathrm{~mm}$ and a mark on the circumferential direction at a distance of $10 \mathrm{~mm}$ from the edge where the cover will be inserted.

2. Place the force sensor on the movable cross-member of the press and place the cylinder over the sensor.

3. Insert the gasket cover into the cylinder until the first gasket comes into contact with the cylinder, this being the initial position.

4. Tighten the mounting rings of the displacement sensor on the cylinder and the gasket cover.

5. Mount the displacement sensor between the rings.

6. Start the press, compressing the cylinder-lid assembly until the lid is completely inserted into the cylinder (both gaskets in the lid channels are inside the cylinder, and the shoulder of the lid has come into contact with the cylinder).

\section{Experimental Results}

For the experimental determination of the assembly force, for the axial force, the HBM U10M 125K force sensor (Hottinger Brüel \& Kjaer GmbH, Germany) was used, over which the cylinder was placed, with the whole assembly works in compression. In the upper side of the cylinder, a lid with the gaskets assembled in the channels was positioned, and it was pushed into the cylinder by the hydraulic press.

Plastic clamps were attached to the lid with gaskets and to the cylinder body, between which the HBM WA 100mm displacement sensor was mounted (Figure 7).

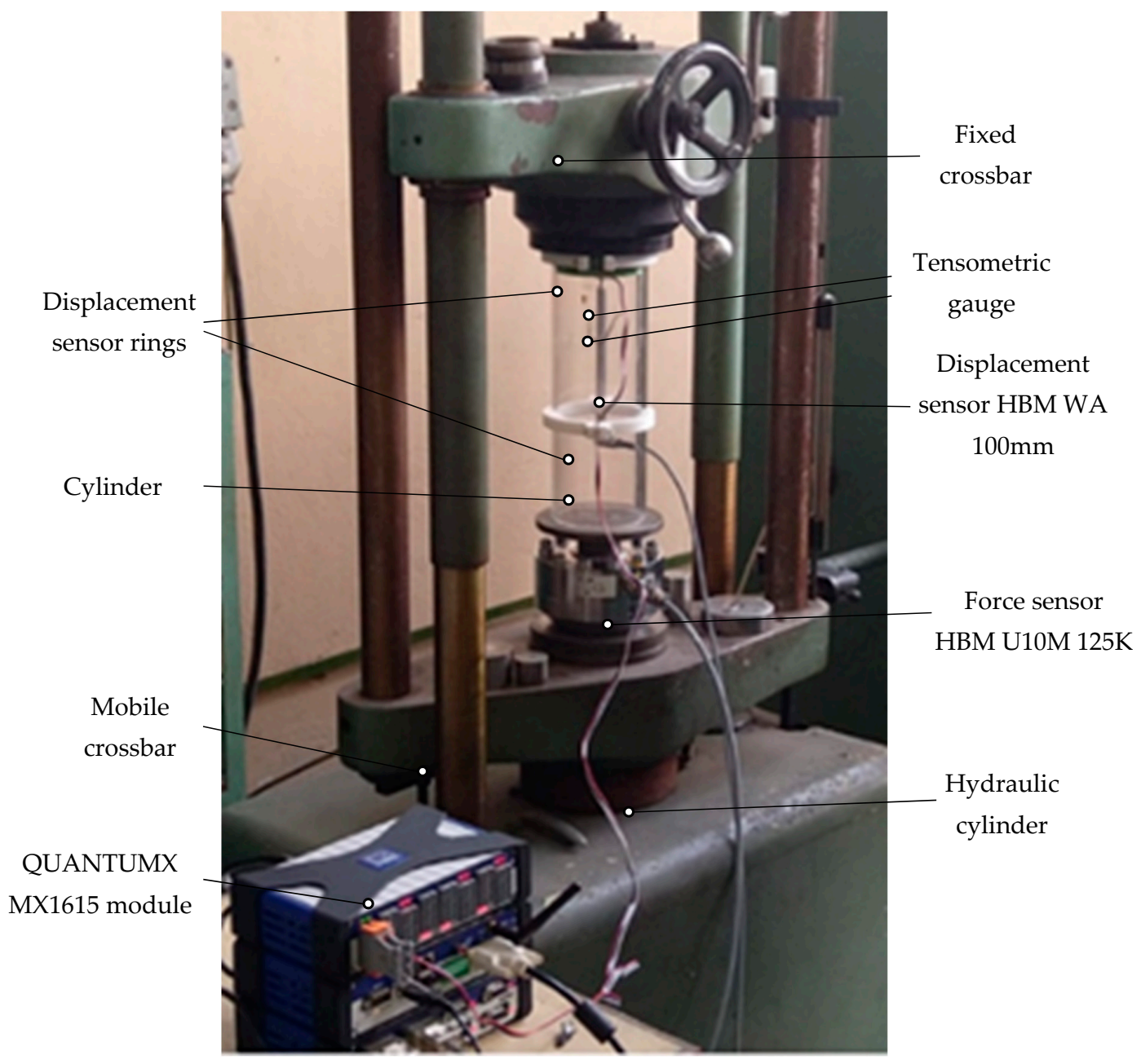

Figure 7. Cylinder positioned over the force sensor. 
In the upper side of the cylinder, in the area where the lid entered, two tensometric marks of $120 \Omega$ were glued on the outside of the cylinder, one in the axial direction with the center of the active part at $40 \mathrm{~mm}$ from the upper side of the cylinder, and one in the circumferential direction with the mark measurement axis at $10 \mathrm{~mm}$ (Figure 8). The marks were connected to the QUANTUMX MX1615 module, and the force and displacement sensors to the MX840B module. Data acquisition was performed at a frequency of $50 \mathrm{~Hz}$.

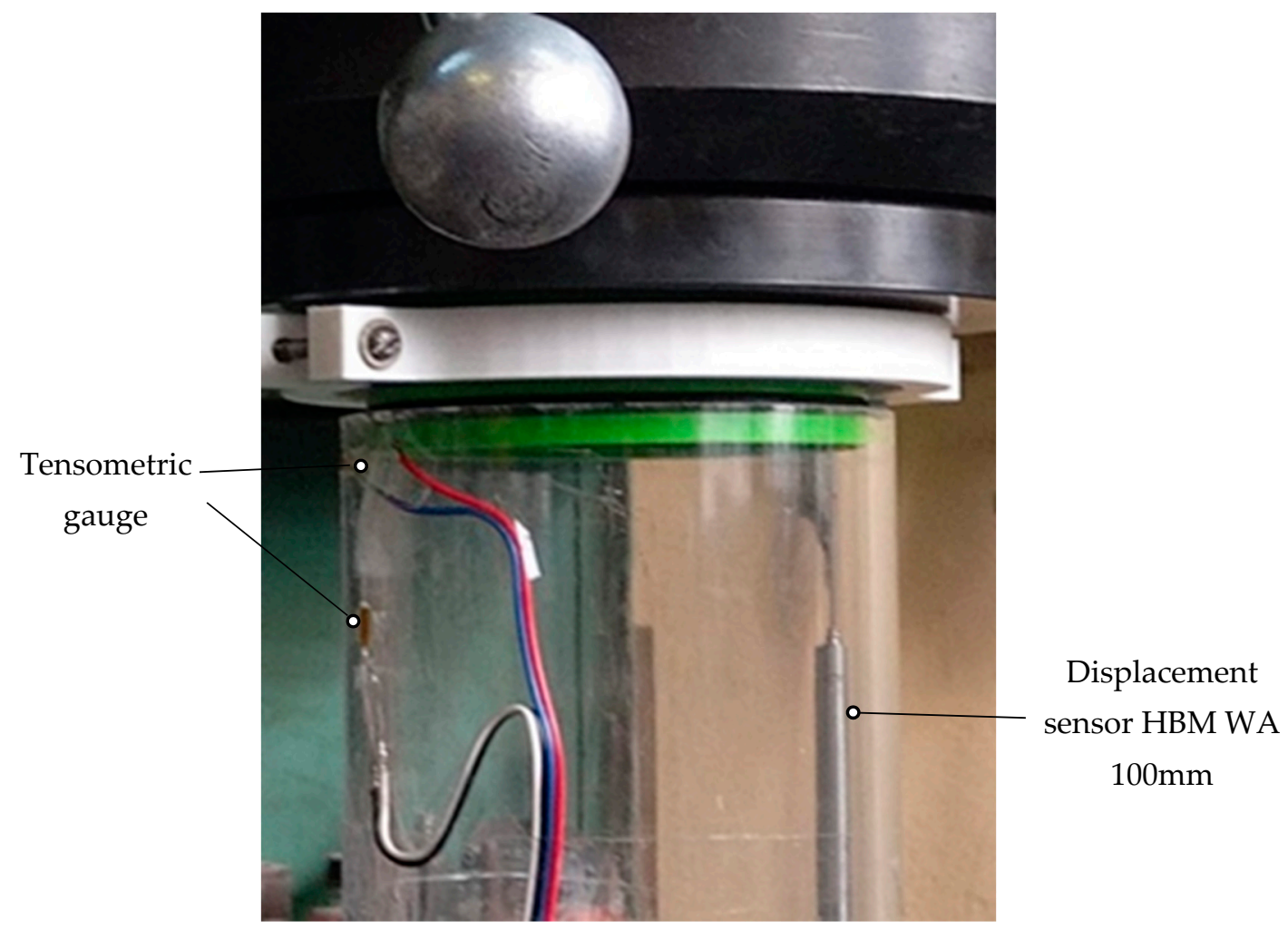

Figure 8. Cylinder detail in the area of tensometric marks.

Two types of tests were performed: one in which the gaskets and the inner surface of the cylinder were dry; another in which the gaskets were lubricated with oil for the fine mechanisms.

In the following graphs, the signal from the axially positioned tensometric mark is multiplied by the modulus of elasticity of the cylinder and by the cross-sectional area, thus obtaining, assuming the uniform distribution of normal tension on the cross-section of the cylinder, an axial force.

In the case of dry friction, there was a slip-stick movement of the lid, which is shown in the graphs in Figures 9 and 10, after the displacement of the lid exceeded $5 \mathrm{~mm}$, through sudden variations in displacement and, consequently, force and specific deformations. In this case, there was hanging of the first gasket, which was partially removed from the channel and crushed between the body of the lid and the cylinder, an aspect noted in the numerical simulations. 


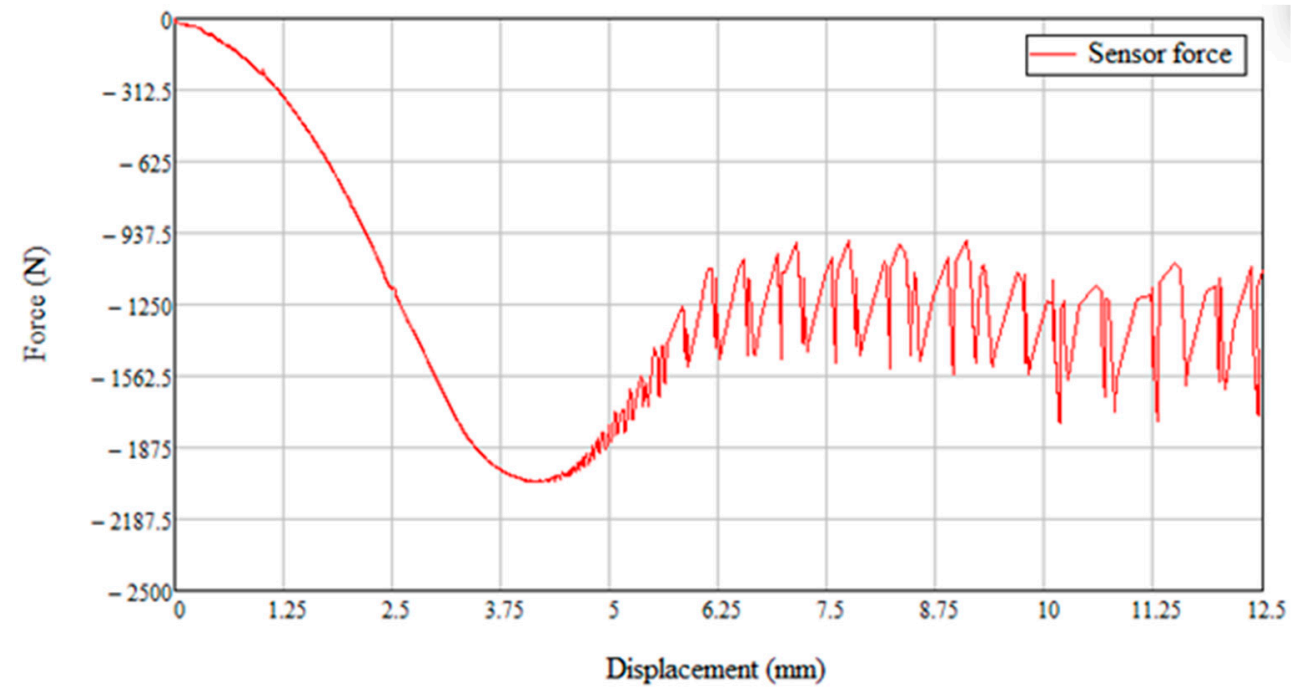

Figure 9. Axial force measured by the force sensor as a function of the displacement of the cover for the oil-free assembly case.

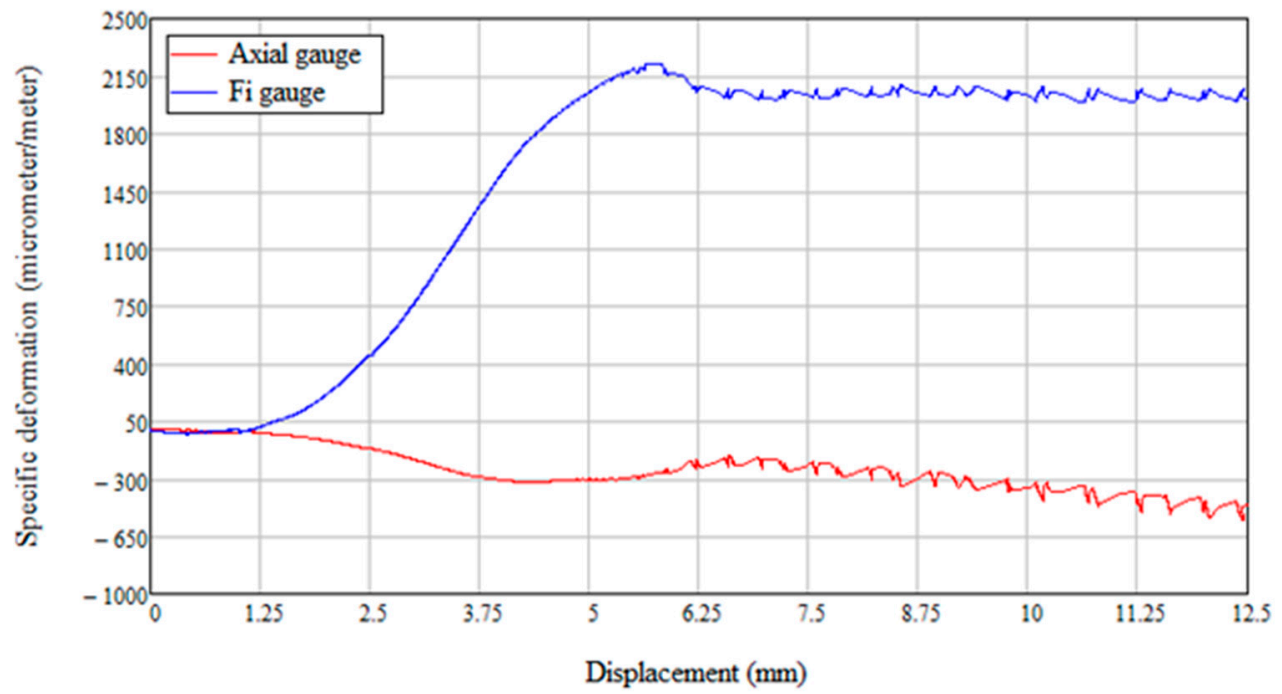

Figure 10. Specific deformations on the axial direction and the circumference in the case of oil-free assembly.

In this situation, the radial expansion of the cylinder was high, and there was a danger of cracking the cylinder.

In the case of mounting with lubricated gaskets, there was a continuous movement of the lid in the cylinder; the first gasket that came into contact with the cylinder was no longer driven between the cover and the cylinder.

Since the gasket was no longer caught between the lid and the cylinder, the radial expansion of the cylinder in the area of contact with the gasket was much reduced due to the compression of the gaskets in the channels in the lid.

Consequently, there was a decrease in mounting force and specific deformations in the axial and radial direction (Figure 11). 


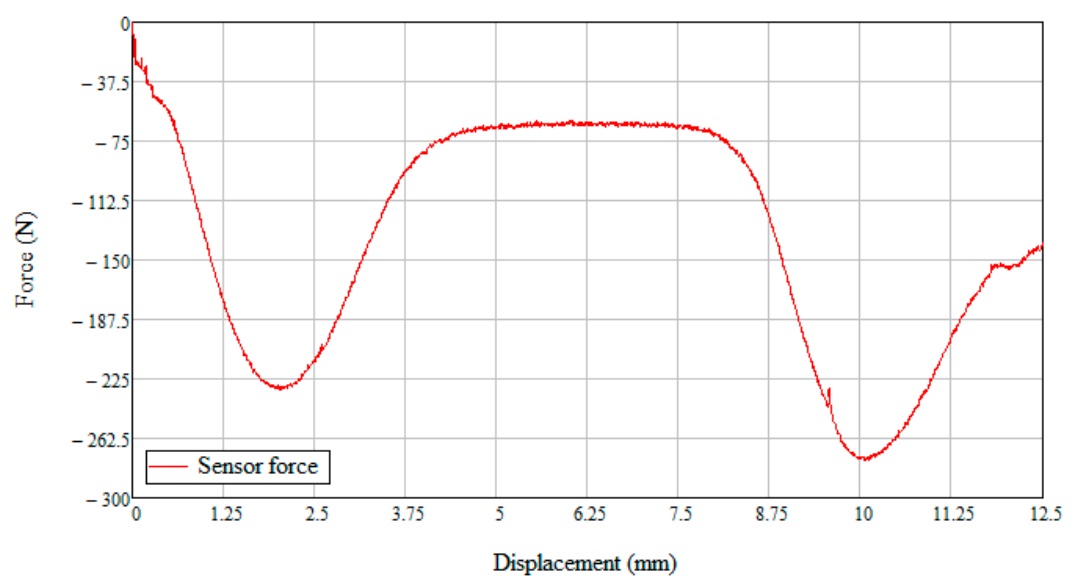

Figure 11. Axial force measured by the force sensor as a function of the displacement of the lid for the lubricated mounting.

In this situation, the danger of cracking the cylinder is much reduced, with the circumferential and radial stresses reduced compared to a situation in which no oil is used.

Figure 12 shows the variations depending on the displacement of the specific deformations obtained numerically and experimentally.
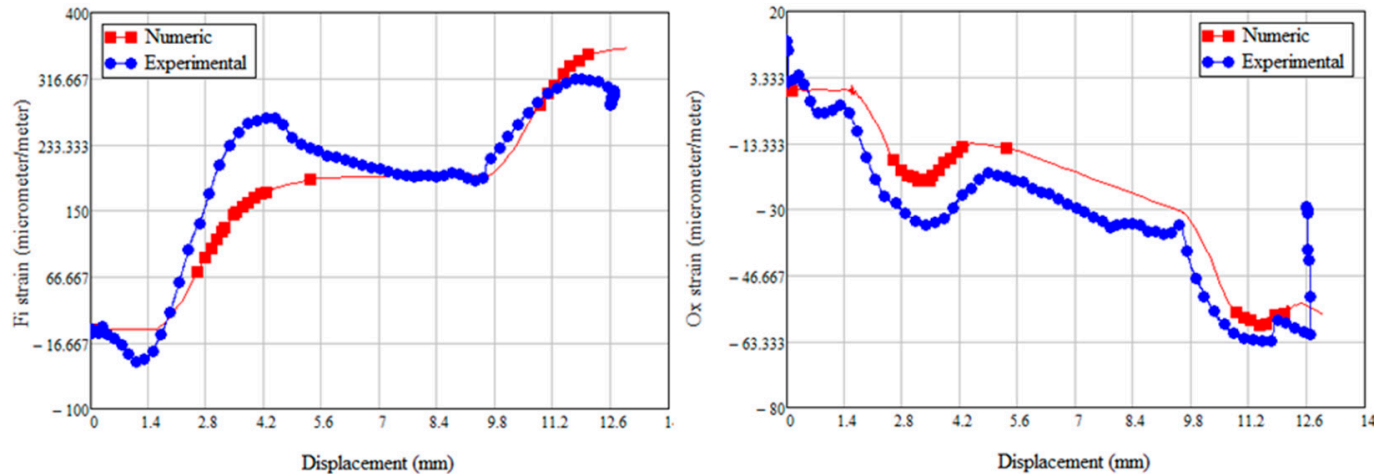

Figure 12. Specific deformations on the axial direction and the circumference depending on the displacement of the cover for the case of oil mounting, compared to the numerical simulations.

To make this comparison of the numerical determinations with the experimental ones, the time variations of the specific deformations recorded by the tensometric marks were scaled (the numerical calculation time differs from the completion time of the experimental test).

\section{Conclusions}

In the case of the assembly of the lid with unlubricated gaskets, the first gasket that comes into contact with the cylinder is partially moved between the lid and the cylinder, inflating the cylinder towards the end. Thus, the second gasket that enters the cylinder creates a reduced contact area with the cylinder, meaning its efficiency in sealing is reduced and even compromised. For the first gasket, some crushed/broken areas can be noted, containing narrow material strips-with sections of $0.2-0.3 \mathrm{~mm}$ and lengths of approximately $10 \mathrm{~mm}$ - that were initially fixed between the two bodies. The maximum force corresponding to a lid displacement of $4.15 \mathrm{~mm}$ is $2026 \mathrm{~N}$.

For oil mounting, it is observed that the axial mounting force decreases. In the graph in Figure 11, we can distinguish how it reaches two end points, which are corresponding to the maximum settlement of the two gaskets between the walls of the channels in the cover and the cylinder body. For the first gasket coming into contact, a force of $230.7 \mathrm{~N}$ is reached 
at a lid displacement of $2.04 \mathrm{~mm}$, and for the second gasket, a force of $276.5 \mathrm{~N}$ corresponds to a displacement of $10.06 \mathrm{~mm}$.

After each test, the press is discharged and the pressing force becomes zero, but the former assembly remains tensioned due to the pressing of the gaskets between the cover body and the cylinder. The axial stress becomes zero, so the cylinder remains tensioned in the contact area with the gaskets. The specific deformations on the circumference, on the outside of the cylinder, when measured after the assembly are $2067\left[\frac{\mu \mathrm{m}}{\mathrm{m}}\right]$ for the oil-free mounting and $306.8\left[\frac{\mu \mathrm{m}}{\mathrm{m}}\right]$ for the oil mounting.

The study was necessary to achieve a configuration that meets both economic and resistance criteria. From a technological point of view, the chosen solution is simple to achieve.

Considering the obtained results, we propose, for the future, a numerical and experimental study of the stability of the structure at uniform triaxial compression. We also intend to try other thermoplastic materials to test their efficacy for making sealing components.

Author Contributions: Conceptualization, A.-G.S., L.S.G., S.M., I.P. and I.O.; methodology, I.O.; software, I.P.; validation, A.-G.S., L.S.G. and S.M.; formal analysis, A.-G.Ș., L.S.G.G and I.O.; investigation, A.-G.S., L.S.G. and S.M.; writing-original draft preparation, A.-G.Ș. and L.Ș.G.; writing-review and editing, I.O. and S.M.; visualization, I.O. and I.P.; supervision, A.-G.S.; project administration, A.-G.S., L.Ș.G., S.M., I.P. and I.O. All authors have read and agreed to the published version of the manuscript.

Funding: This research received no external funding.

Institutional Review Board Statement: Not applicable.

Informed Consent Statement: Not applicable.

Data Availability Statement: Not applicable.

Acknowledgments: We are grateful to the Military Technical Academy's Center of Excellence in Robotics and Autonomous Systems (CERAS), for making the project data available: "ERL Emergency project: UGV and ROUV". We also thank the team members of the ROUV implementation: Molder, C., Gorgoteanu, D., Constantin, D., Molder (Milășan) A., Stoica, P., Focșa, A., and all the others.

Conflicts of Interest: The authors declare no conflict of interest.

\section{References}

1. Glotzbach, T.; Eckstein, S.; Ament, C. An approach for planning a safe mission begin and end for teams of marine robots. IFAC-Pap. OnLine 2015, 48, 100-106. [CrossRef]

2. Gonzalez, L.A. Design, Modelling and Control of an Autonomous Underwater Vehicle. Bachelor's Thesis, Centre for Intelligent Information Processing Systems, School of Electrical, Electronic and Computer Engineering, The University of Western, Crawley, Australia, 2004; p. 156. Available online: http:/ / robotics.ee.uwa.edu.au/theses/2004-AUV-Gonzalez.pdf (accessed on 1 June 2021).

3. Capocci, R.; Omerdić, E.; Dooly, G.; Toal, D. Development and testing of remotely operated vehicle for inspection of offshore renewable devices. In Technological Innovation for Resilient Systems, Part of IFIP Advances in Information and Communication Technology, Proceedings of the Doctoral Conference on Computing, Electrical and Industrial Systems DoCEIS 2018, Costa de Caparica, Portugal, 2-4 May 2018; Camarinha-Matos, L.M., Kanham, O., Adu-Kankam, Julashokri, M., Eds.; Springer: Cham, Switzerland, 2018; Volume 521, pp. 282-289. [CrossRef]

4. Van der Berg, J.; Lin, M.; Manocha, D. Reciprocal Velocity Obstacles for Real-Time Multi-Agent Navigation. In Proceedings of the IEEE International Conference on Robotics and Automation, ICRA 2008, Pasadena, CA, USA, 19-23 May 2008; pp. 1928-1935, ISBN 978-1-4244-1646-2. Available online: https://www.cse.iitk.ac.in/users/cs365/2014/_papers/vandenberg-lin-manocha08_ reciprocal-velocity-obstacles.pdf (accessed on 4 June 2021). [CrossRef]

5. Rodríguez-Molina, J.; Bilbao, S.; Martínez, B.; Frasheri, M.; Cürüklü, B. An optimized, data distribution service-based solution for reliable data exchange among autonomous underwater vehicles. Sensors 2017, 17, 1802. [CrossRef] [PubMed]

6. Capocci, R.; Omerdić, E.; Dooly, G.; Coleman, J.; Toal, D. Smart inspection ROV for use in challenging conditions. In Proceedings of the Conference: OCEANS 2015-MTS/IEEE Washington, Washington, DC, USA, 19-22 October 2015; Volume 15798944, pp. 1-7. [CrossRef]

7. Sívčev, S.; Rossi, M.; Coleman, J.; Omerdić, E.; Dooly, G.; Toal, D. Collision detection for underwater ROV manipulator systems. Sensors 2018, 18, 1117. [CrossRef] 
8. Casalino, G.; Simetti, E.; Manerikar, N.; Sperinde, A.; Torelli, S.; Wanderlingh, F. Cooperative underwater manipulation systems: Control developments within the MARIS project. In Proceedings of the Conference 4th IFAC Workshop on Navigation, Guidance and Control. of Underwater Vehicles NGUV 2015, Girona, Spain, 28-30 April 2015; Volume 48, pp. 001-007. [CrossRef]

9. González-García, J.; Gómez-Espinosa, A.; Cuan-Urquizo, E.; García-Valdovinos, L.G.; Salgado-Jiménez, T.; Cabello, J.A.E. Autonomous underwater vehicles: Localization, navigation, and communications for collaborative missions. Appl. Sci. 2020, 10, 1256. [CrossRef]

10. Cyril, C.; Aaltonen, J.; Escusol, J.V. Autonomous and Collaborative Offshore Robotics. In Proceedings of the 2nd Annual SMACC Research Seminar 2017, Tampere, Finland, 10 October 2016; Tampere University of Technology, 2017. pp. 57-59. Available online: https:/ / techfinland100.fi/mita-rahoitamme/tutkimus/tulevaisuuden-tekijat/autonomous-and-collaborativeoffshore-robotics-acolor/ (accessed on 13 June 2021).

11. Mai, C.; Pedersen, S.; Hansen, L.; Jepsen, K.; Yang, Z. Subsea infrastructure inspection: A review study. In Proceedings of the 6th International Conference on Underwater System Technology: Theory and Applications, Penang, Malaysia, 13-14 December 2016. [CrossRef]

12. Al-Taie, I.; Alsaiari, H.A.; Amer, A.; Abdellatif, F.; Outa, A.; Trigui, H.; Ledezma, F.D.; Patel, S.; Abedan, A. Survey of underwater ndt technologies for offshore assets. In Proceedings of the 7th Middle East. Nondestructive Testing Conference \& Exhibition, Manama, Bahrain, 13-16 September 2015. Available online: https://www.researchgate.net/publication/311017742_Survey_of_ Underwater_NDT_Technologies_for_Offshore_Assets (accessed on 20 June 2021).

13. Capoci, R.; Dooly, G.; Omerdić, E.; Coleman, J.; Newe, T.; Toal, D. Inspection-Class remotely operated vehicles-A review. Mar. Sci. Eng. 2017, 5, 13. [CrossRef]

14. Kohut, P.; Giergiel, M.; Cieslak, P.; Ciszewski, M.; Buratowski, T. Underwater robotic system for reservoir maintenance. JVE Int. Ltd. J. Vibrengineering 2016, 18, 3757-3767. [CrossRef]

15. Ru, J.; Yu, S.; Wu, H.; Li, Y.; Wu, C.; Jia, Z.; Xu, H. A Multi-AUV Path Planning System Based on the Omni-Directional Sensing Ability. J. Mar. Sci. Eng. 2021, 9, 806. [CrossRef]

16. Omerdic, E.; Toal, D.; Dooly, G. OceanRINGS: Smart technologies for subsea operations. In Advanced in Marine Robotics; LAP LAMBERT Academic Publishing, Mobile \& Marine Robotics Research Centre, University of Limerick: Limerick, Ireland, 2013.

17. Rubino, E.M.; Centelles, D.; Sales, J.; Marti, J.V.; Marin, R.; Sanz, P.J. Wireless Image compression and transmission for underwater robotic applications. IFAC Pap. OnLine 2015, 48, 288-293. [CrossRef]

18. Langer, R.A.; von der Weid, J.P.; Marnet, R. Autonomous underwater riser inspection tool. In Proceedings of the 8th International Pipeline Conference IPC2010, Calgary, AB, Canada, 27 September-1 October 2010; p. 7, IPC2010-31485. [CrossRef]

19. Hwang, J.; Bose, N.; Fan, S. AUV adaptive sampling methods: A review. Appl. Sci. 2019, 9, 3145. [CrossRef]

20. Kawamura, S. Underwater Robot Development for Manipulation Task and their Uses in Biwa Lake. IFAC Pap. OnLine 2015, 48, 14-19. [CrossRef]

21. Li, J.-H.; Lee, M.-J.; Kang, H.; Kim, M.-G.; Cho, G.R. Design, performance evaluation and field test of a water jet tool for ROV trencher. J. Mar. Sci. Eng. 2021, 9, 296. [CrossRef]

22. Li, J.H.; Kim, J.Y.; Lee, M.J.; Lee, W.S.; Kang, H.J.; Han, H.C.; Lee, J.W.; Kwak, H.H. Conceptual design of optimal thrust system for efficient cable burying of ROV trencher. In Proceedings of the MTS/IEEE Oceans, St. John's, NL, Canada, 14-19 September 2014; pp. 1-5. [CrossRef]

23. Cho, G.R.; Lee, M.J.; Kang, H.; Ki, G.; Kim, M.G.; Li, J.H. Evaluation of underwater cable burying rov through sea trial at east sea. In Proceedings of the IFAC World Congress 2020, Berlin, Germany, 12-17 July 2020; Volume 53, pp. 9658-9663. [CrossRef]

24. Committee on Autonomous Vehicles in Support of Naval Operations; Naval Studies Board; Division on Engineering and Physical Sciences. Autonomous Vehicles in Support of Naval Operations; National Research Council: Washington, DC, USA, 2005; p. 256, ISBN 978-0-309-38616-6. [CrossRef]

25. Yang, Z.; Cao, Y.; Liu, J. A Buckling Analysis and Optimization Method for a Variable Stiffness Cylindrical Pressure Shell of AUV. J. Mar. Sci. Eng. 2021, 9, 637. [CrossRef]

26. Campagnaro, F.; Signori, A.; Zorzi, M. Wireless remote control for underwater vehicles. J. Mar. Sci. Eng. 2020, 8, 736. [CrossRef]

27. Aristizábal, L.M.; Zuluaga, C.A.; Rúa, S.; Vásquez, R.E. Modular hardware architecture for the development of underwater vehicles based on systems engineering. J. Mar. Sci. Eng. 2021, 9, 516. [CrossRef]

28. Wang, Y.-L.; Lu, C.-Y. Design and parameter estimation of a remotely operated underwater vehicle. J. Mar. Eng. Technol. 2012, 11,39-48. [CrossRef]

29. Djapic, V.; Dong, W.; Spaccini, D.; Cario, G.; Casavola, A.; Gjanci, P.; Lupia, M.; Petrioli, C. Cooperation of coordinated teams of autonomous underwater vehicles. IFAC Pap. OnLine 2016, 49, 088-093. [CrossRef]

30. Yao, Y. Cooperative navigation system for multiple unmanned underwater vehicles. In Proceedings of the 3rd IFAC International Conference on Intelligent Control. and Automation Science, Chengdu, China, 2-4 September 2013; ISBN 978-3-902823-45-8/2013. [CrossRef]

31. Benjamin, M.R.; Curcio, J.A. COLREGS-Based navigation of autonomous marine vehicles. In Autonomous Underwater Vehicles; IEEE/OES: Sebasco, ME, USA, 2004; pp. 32-39. Available online: https://ieeexplore.ieee.org/abstract/document/1431190 (accessed on 4 August 2021). [CrossRef]

32. Cho, H.; Jeong, S.-K.; Ji, D.-H.; Tran, N.-H.; Vu, M.T.; Choi, H.-S. Study on control system of integrated unmanned surface vehicle and underwater vehicle. Sensors 2020, 20, 2633. [CrossRef] 
33. Liu, Y.; Wang, M.; Su, Z.; Luo, J.; Xie, S.; Peng, Y.; Pu, H.; Xie, J.; Zhou, R. Multi-AUVs cooperative target search based on autonomous cooperative search learning algorithm. J. Mar. Sci. Eng. 2020, 8, 843. [CrossRef]

34. Meschini, A.; Ridolfi, A.; Gelli, J.; Pagliai, M.; Rindi, A. Pressure hull design methods for unmanned underwater vehicles. J. Mar. Sci. Eng. 2019, 7, 382. [CrossRef]

35. Chruściel, T.; Ciba, E.; Dopke, J. CFD and FEM modelo f an underwater vehicle propeller. Pol. Marit. Res. 2014, 21 , 40-45. [CrossRef]

36. Cely, J.S.; Saltaren, R.; Portilla, G.; Yakrangi, O.; Rodriguez-Barroso, A. Experimental and computational methodology for the determination of hydrodynamic coefficients based on free decay test: Application to conception and control of underwater robots. Sensors 2019, 19, 3631. [CrossRef] [PubMed]

37. Grigore, L.S.; Stefan, A.G.; Orban, O. Using PET-G to design an underwater Rover through 3D printing technolofy. Mater. Plast. 2020, 57, 189-201. [CrossRef]

38. Blintsov, V.; Aloba, L.T. Control automation of maritime unmanned complex with a group of autonomous underwater vehicles. EUREKA Phys. Eng. 2019, 4, 54-62. [CrossRef]

39. Medvešek, I.G.; Vujovic, I.; Šoda, J.; Krcum, M. A novel method on hydrographic survey technology selection based on the decision tree supervised learning. Appl. Sci. 2021, 11, 4966. [CrossRef]

40. Blue Rov Solutions. Available online: https:/ / bluerov-solutions.com/ (accessed on 22 June 2021).

41. Balaji, V.; Ravi, S.; Naveen Chandran, P. FEM method structural analysis of pressure hull by using hyper mesh. Int. J. Eng. Technol. 2018, 7, 258-263. [CrossRef]

42. Deng, F.; Levi, C.; Yin, H.; Duan, M. Identification of an Autonomous Underwater Vehicle hydrodynamic model using three Kalman filters. Ocean Eng. 2021, 229, 108962. [CrossRef]

43. International Standard. ISO 527-1. In Platics-Determination of Tensile Properties, 2nd ed.; ISO: Geneva, Switzerland, 2012.

44. Timoshenko, S.; Woinowsky-Krieger, S. Theory of Plates and Shells, International ed.; The National Academies of Sciences, Engineering, and Medicine: Tokyo, Japan, 1959; ISBN 0-07-085820-9. Available online: https://trid.trb.org/view/102979 (accessed on 4 August 2021). 